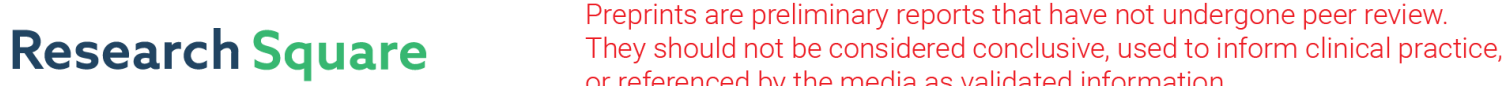 or referenced by the media as validated information. \\ Intelligent speed control of a Stirling engine using artificial neural network
}

Mohammadreza Hojati ( $\nabla$ hojati.mohammadreza@gmail.com )

Arak University https://orcid.org/0000-0003-1527-7355

Ehsan Mansouri

Arak University

\section{Research Article}

Keywords: Artificial intelligence, Neural network, Intelligent Speed control, LTD Stirling engine

Posted Date: May 20th, 2021

DOl: https://doi.org/10.21203/rs.3.rs-494225/v1

License: (9) This work is licensed under a Creative Commons Attribution 4.0 International License. Read Full License 


\title{
Intelligent speed control of a Stirling engine using artificial neural network
}

\author{
Mohammadreza Hojati ${ }^{1}$, Ehsan Mansouri ${ }^{1}$
}

\begin{abstract}
The Stirling engine is a kind of external combustion engine that is ideal for converting renewable energies to electricity or mechanical energy forms. Therefore, monitoring and controlling some of its parameters such as its speed is important. The purpose of this paper is to control a Stirling engine flywheel rotation speed using an intelligent parameter predictor. Since various parameters affect motor performance, determining the optimal value of them manually is impossible. Therefore, linking these parameters together and finding a relationship between them would be beneficial. Hence, using artificial intelligence (AI) to find a quick and efficient solution is particularly important. At the studied Stirling engine, speed, cold sink and ambient temperatures are defined as input parameters, and hot sink temperature is considered as the output parameter that should be calculated. To discover the relationship between inputs and output, an artificial neural network (ANN) is used. The results of this study showed that the use of ANNs can be significantly helpful in controlling engine speed.
\end{abstract}

Keywords Artificial intelligence. Neural network. Intelligent Speed control . LTD Stirling engine

\section{Introduction}

The energy crisis is one of the most important problems in the world that has affected people`s lives significantly. One of the ways to cope with this problem is to use renewable energy sources such as solar energy, biomass, and wind energy. A lot of efforts have been made to make useful converters that can work by heat sources with low temperature differences, which is necessary for use in most renewable sources. These efforts have led researchers to use Stirling engines $[1,2]$. During the $20^{\text {th }}$ century, at the same time with the development of internal combustion engines and electrical motors, Stirling engines have been developed dramatically, as well [2].

The Stirling engine compared with other types of heat engines is known as one of the most efficient ones with high performance. Operation of the Stirling engine is based on compression and expansion of a working fluid such as hydrogen, air, or helium in two cylinders and with two pistons which have angular phase difference that causes the working fluid to move through these two cylinders. Various factors such as physical properties and working fluid temperature, heat transfer coefficients, the temperature difference between hot and cold sources, regenerator efficiency, mechanical joints properties, working pressure,

Mohammadreza Hojati
hojati.mohammadreza@gmail.com

1 Faculty of Engineering, Arak University, Arak, Iran and engine ratio of impermeability can affect the engine performance and its efficiency [3].

Solar energy is one of the most beneficial energy sources to run a Stirling engine. There are different ways to utilize this clean and accessible source of energy. For instance, flat and concentrating collectors are two useful means for harnessing solar energy to be used for these engines. Flat collectors are used for low temperature differential (LTD) Stirling engines and concentrating collectors are used for high temperature differential (HTD) ones. LTD engines have attracted much attention in developing countries for uses like power generation and water pumping [1].

Various parameters can affect Stirling engine performance and are effective in optimizing engine efficiency. Produced torque is the most important parameter among [2]. For optimizing the Stirling engine parameters, there are many methods such as finite element method (FEM), Genetic Algorithm (GA), and Taguchi method [2]. Another method that can be named is the artificial neural network (ANN) that is used for estimating engine parameters [1, 2]. The reason for using these methods is not only for optimizing the engine parameters which leads to decreasing financial expenses but also for decreasing the time of the optimization process [3].

Neural networks have the ability to model complex nonlinear systems and this is why they are used for the problems that can be solved by using input and output system data instead of mathematical equations and this is the reason that scientists and engineers are interested in it $[1,2]$. The neural network can be used in all the fields that are about optimization, signal processing, manufacturing, and production lines, and power plants [2, 3]. 
Nomenclature [1]

\begin{tabular}{|c|c|c|c|}
\hline \multicolumn{2}{|l|}{ Symbols } & \multicolumn{2}{|c|}{ Subscripts and superscripts } \\
\hline \multirow{2}{*}{$H$} & \multirow{2}{*}{$\begin{array}{l}\text { convective heat transfer coefficient } \\
w / m^{2} K\end{array}$} & $C$ & cold sink \\
\hline & & $c$ & cold gas \\
\hline$P$ & instantaneous pressure $(\mathrm{Pa})$ & $H$ & hot sink \\
\hline$M$ & total gas mass inside the engine $(\mathrm{Kg})$ & $d$ & displacer piston \\
\hline$V$ & volume $\left(\mathrm{m}^{3}\right)$ & $p$ & power piston \\
\hline$T$ & temperature $(\mathrm{K})$ & reg & regenerator \\
\hline$R$ & gas constant $\mathrm{J} / \mathrm{kgK}$ & $d s$ & dead space \\
\hline$S$ & cross sectional area $\left(\mathrm{m}^{2}\right)$ & & \\
\hline$X$ & liquid piston position (m) & \multicolumn{2}{|c|}{ Greek letters } \\
\hline$Y$ & displacer piston position (m) & $\Delta$ & difference \\
\hline Power & generated power $(w)$ & $v$ & frequency \\
\hline$x_{0}$ & $\begin{array}{l}\text { maximum displacement of power piston } \\
\text { (m) }\end{array}$ & $\gamma$ & heat capacity ratio of working fluid \\
\hline \multirow[t]{2}{*}{$y_{0}$} & $\begin{array}{l}\text { maximum displacement of displacer } \\
\text { piston }(\mathrm{m})\end{array}$ & $\eta_{\text {reg }}$ & regenerator efficiency \\
\hline & & $\omega$ & rotational speed \\
\hline
\end{tabular}

The first step for using neural network technology to control a Stirling engine has been done by TavakolpourSaleh et al. [1]. They have implemented a neural network model on a liquid piston solar Stirling engine with a new design so that according to different working conditions, the maximum output power can be taken from the engine intelligently. One of the tasks of the system is to control the working speed of the engine based on different temperature conditions in the hot and cold sources of the engine. Ahmadi et al. [2], have used a neural network to estimate the torque of a Stirling engine. They have prepared a highperformance predicting tool to determine the system variables with high speed and accuracy. The neural network designed by them has a high level of resistance to system changes and uncertainties and it is very useful for Stirling engine designers. Also, Ahmadi et al. [3], for the first time have used an intelligent model as a means of predicting, to estimate output power and torque of a Stirling engine.

Ozgoren et al. [4] have used a neural network to predict the amount of torque and power of a Stirling engine type beta with helium as working fluid. They could obtain the best results by using 5-11-7-1 and 5-13-7-1 with two hidden layers structure of back-propagation type. Ahmadi et al. [5] have used the neural network method, GA, and particle swarm optimization to estimate the power of a solar Stirling engine. Their aim for using this method is to create an optimized neural network and to avoid incomplete and imperfect convergences and according to the results, their method has been successful. Balabin et al. [6] have used neural network tools (nntools) in MATLAB to analyze biodiesel fuel which is one of the useful fuels for the Stirling engines. They could build an efficient model of biodiesel fuel. The results of this research indicated the superiority of the neural network compared to linear methods such as multiple linear regression (MLR), polymerase chain reaction (PCR), partial least squares (PLS), and nonlinear methods such as quasi-nonlinear (poly-PLS, Spline-PLS). Chouai et al. [7] have used a neural network to model thermodynamic properties of refrigerants' which are used in Stirling engines. They could obtain the values of refrigerants thermodynamic properties by using the neural network especially entropy and enthalpy for refrigerants R134a, R32, and R143a. The model obtained in this study can be used as a design tool.

Jokar et al. [8] have made a water pump by using a low temperature Stirling engine and solar energy. This project is a combination of a Fluidyne and a Stirling engine type gamma with adjustable frequency for pumping water. They were able to pump water to a height of 1.5 meters by this method. Ahmadi et al. [9] have used GA for thermal and economic optimization of a Stirling engine. They could maximize the engine performance index and its heat load by using multi-objective optimization and nondominated sorting genetic algorithm II (NSGA-II) methods. Toghyani et al. [10] have used GA to optimize heat exchanger performance. They have used the adiabatic analysis to determine power losses and performance of a Stirling engine. They showed that the multi-objective and multivariable method is capable of designing the Stirling engine. Ahmadi et al. [11] have used the NSGA algorithm and finite speed thermodynamic analysis to optimize Stirling 
engine efficiency and its output power and minimize pressure losses. Ahmadi et al. [12] have used an evolutionary algorithm to maximize two objective functions including output power and overall thermal efficiency and to minimize entropy generation rate at the same time. They investigated the best answer using several selector methods including fuzzy logic, the linear programming technique for multidimensional analysis of preference (LINMAP), and the technique for order of preference by similarity to ideal solution (TOPSIS). The result they achieved was that by using the multi-objective and multi-variable method, designing an engine can be well done and it is because of highly accurate and precise results obtained from this method.

Li et al. [13] have used GA to obtain Pareto frontiers in a gamma type Stirling engine to optimize it and then by using decision-making methods like LINMAP and TOPSIS, they found the optimal points and they could reach entropy generation rate to $1 / 12$ by using this method. Ahmadi et al. [14] have used finite speed thermodynamic analysis instead of finite time thermodynamic analysis to optimize Stirling engine parameters and the obtained results have proven the superiority of this method. Patel et al. [15] have used the teaching-learning-based optimization (TS-TLBO) algorithm to optimize Stirling engine parameters. In this study, eleven geometric and operational variables were examined and optimized. The results of this research have shown that the algorithm presented in this article can easily accept changes needed for similar issues and then can be applied to them.

Arora et al. [16] have optimized the parameters of a solar Stirling engine with a concentrator collector using the NSGA-II algorithm. They could obtain the best values for their desired variables including output power, thermal efficiency, and engine thermo-economic function by 4 decision-making methods including Bellman-Zadeh fuzzy logic, TOPSIS, Shannon`s method, and LINMAP. Ahmadi et al. [17] have used finite time thermodynamic analysis and NSGA-II algorithm to optimize a high temperature solar Stirling engine parameters and at last, they have calculated the final answer using three decision-making methods. Luo et al. [18] have used a combination of 3 methods including differential evolution method, GA, and adaptive simulated annealing to optimize a GPU3 Stirling engine. They have aimed to try to increase the output power and to reduce engine power losses. For the mentioned engine, they succeeded to achieve $3 \mathrm{~kW}$ for power and a $5 \%$ increase in thermal efficiency.

For designing an ANN, the first step is the preparation of training data. It should be noted that the neural network is strongly dependent on the quality of the training data that receives. The data that is used for training and adapting the neural network is divided into three categories and they are training data, validating data, and testing data.

To train a neural network to perform a certain task, the weight of each element can be changed. Finally, the neural network has been trained and output parameters can be calculated based on specific input data. This process continues until the desired results are achieved. It should be noted that there are three main layers in an ANN that are included: (1) input layer, (2) hidden layer, (3) output layer [2]. An example of a multi-layered structure of a neural network is shown in Figure 1.

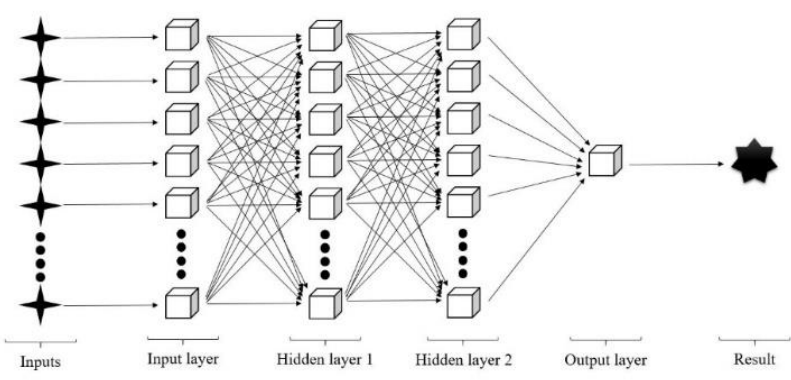

Figure 1 Example of a multi-layer ANN of feed-forward type

The performance of an ANN can be assessed by comparing the predicted output values with desired output values and calculating the error rate. There are many methods to evaluate the performance of a neural network. Some examples of these methods include: error rate, mean square error, relative mean square error, mean relative error [1].

According to the aforementioned resources, there has been no research on controlling the rotation speed of a Stirling engine flywheel in different temperature conditions using ANN, yet. Therefore, in this study, the aim is to control Stirling engine working speed using data given by a feedforward back propagation neural network for the engine's hot sink in different environmental temperature situations so that by applying that temperature level to the hot sink, flywheel rotation speed of the engine, remains constant. The reason for ANN to be used for this purpose is the ability of this network for nonlinear systems modeling and estimation of the parameters in conditions that with usual classic methods, it is not possible to estimate them.

Using a neural network-based intelligent control system starting up an LTD Stirling engine, has several advantages including the following $[1,2]$ :

1. Due to its intelligent control, it is automated and doesn`t need any external operator.

2. The engine because of its smart system, can work in different working conditions and has the best performance in these conditions.

3. If this engine is used for pumping water, its intelligent system is capable of pumping the water with the natural frequency of the water column and this causes resonance in the water column leading to increasing output water flow.

4. This control system can adjust engine parameters so that it can work in conditions close to the Stirling theory cycle.

5. The neural network-based smart control has a high level of resistance and integrity, and reliability in the face of a low level of uncertainty 
in the amount of the engine torque, based on different working conditions.

Therefore in the following, firstly, mathematical and thermodynamic modeling of the engine for designing issues will be discussed. After that, a description of the testbed is used in this study, is presented. And finally, designing and testing of the neural network and conclusion of the research are presented.

\section{Mathematical modeling}

Stirling engine works based on the Stirling cycle. Figure 2 shows the LTD Stirling engine ideal thermodynamic cycle considering the irreversibilities. This cycle consists of two isothermal and two constant volume processes. In order to design a Stirling engine to work with a specific power, it should be designed based on thermodynamic and dynamic equations. For designing the engine Based on Schmidt theory, the following conditions must be assumed [8]:

1. The flow in the outlet pipe is time-unsteady.

2. The flow is laminar and fully developed.

3. The fluid is incompressible.

4. The fluid is Newtonian with constant viscosity.

5. The fluid velocity profile is symmetrical with respect to the center line of the pipes.

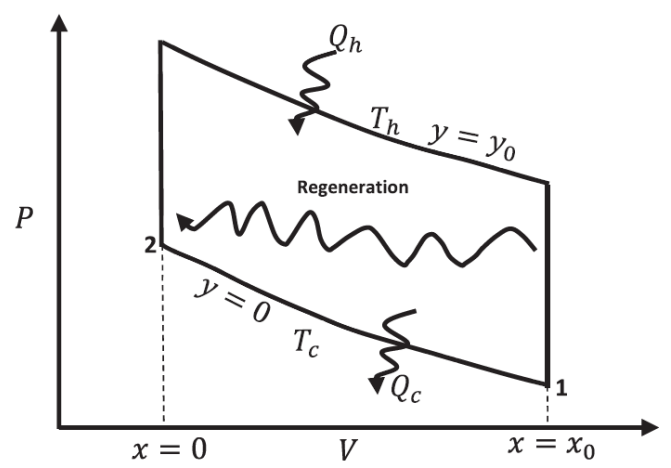

Figure 2 General irreversible Stirling cycle [8]

According to calculation done by Jokar et al. [8], LTD Stirling engine can be modeled as follows:

$$
\begin{aligned}
& m=m_{h}+m_{c}+m_{r e g} \Rightarrow \\
& m \\
& =\frac{P\left(S_{d} y+V_{h d s}\right)}{r T_{h}} \\
& +\frac{P\left(S_{d}\left(y_{0}-y\right)+x S_{p}+V_{c d s}\right)}{r T_{c}}
\end{aligned}
$$

Equation (1) can be rewritten as follows:

$$
\begin{aligned}
& P(x, y) \\
& =\frac{m r T_{c} T_{h}}{T_{h}\left(S_{d}\left(y_{0}-y\right)+x S_{P}+V_{c d s}\right)+T_{c}\left(S_{d} y+V_{h d s}\right)}
\end{aligned}
$$

The total work performed by an engine cycle can be calculated by the following equation:

$$
\begin{aligned}
& W=\oint P S_{P} d x=\int_{x_{0}}^{0} P(x, 0) S_{p} d x \\
& +\int_{0}^{x_{0}} P\left(x, y_{0}\right) S_{p} d x \Rightarrow \\
& \text { W } \\
& =m r T_{c}\left(\ln \left(\frac{T_{c} V_{h d s}+T_{h}\left(V_{c d s}+S_{d} y_{0}\right)}{T_{c}\left(V_{h d s}+S_{d} y_{0}\right)+T_{c} V_{h d s}}\right)\right. \\
& \left.+\ln \left(\frac{T_{c}\left(V_{h d s}+S_{d} T_{c} y_{0}\right)+T_{h}\left(V_{c d s}+S_{P} x_{0}\right)}{T_{c} V_{h d s}+T_{h}\left(V_{c d s}+S_{P} x_{0}+S_{d} y_{0}\right)}\right)\right)
\end{aligned}
$$

$$
\begin{aligned}
& =\frac{m r T_{c}}{T_{c}-T_{h}}\left(\ln \left(\frac{T_{c}\left(V_{h d s}+S_{d} y_{0}\right)+T_{h} V_{c d s}}{T_{c} V_{h d s}+T_{h}\left(V_{c d s}+S_{d} y_{0}\right)}\right)\right. \\
& \left.+\ln \left(\frac{T_{c} V_{h d s}+T_{h}\left(V_{c d s}+S_{P} x_{0}+S_{d} y_{0}\right)}{T_{c}\left(V_{h d s}+S_{d} y_{0}\right)+T_{h}\left(V_{c d s}+S_{P} x_{0}\right)}\right)\right)
\end{aligned}
$$$$
Q_{h}^{\prime}
$$

The heat is released to the cold source during an isothermal compression process, can be calculated as follows:

$$
\begin{aligned}
& Q_{c}^{\prime} \\
& =\frac{-m r T_{c}^{2}}{T_{c}-T_{h}}\left(\ln \left(\frac{T_{c}\left(V_{h d s}+S_{d} y_{0}\right)+T_{h} V_{c d s}}{T_{c} V_{h d s}+T_{h}\left(V_{c d s}+S_{d} y_{0}\right)}\right)\right. \\
& \left.+\ln \left(\frac{T_{c} V_{h d s}+T_{h}\left(V_{c d s}+S_{P} x_{0}+S_{d} y_{0}\right)}{T_{c}\left(V_{h d s}+S_{d} y_{0}\right)+T_{h}\left(V_{c d s}+S_{P} x_{0}\right)}\right)\right)
\end{aligned}
$$

The heat stored in regenerator is as follows:

$$
Q_{r e g}=\Delta m C_{v}\left(T_{h}-T_{c}\right)=\Delta m \frac{r}{\gamma-1}\left(T_{h}-T_{c}\right)
$$

$\Delta m$

$$
\begin{aligned}
& =\frac{m T_{c}\left(V_{h d s}+S_{d} y_{0}\right)}{T_{h} V_{c d s}+T_{c}\left(V_{h d s}+S_{d} y_{0}\right)} \\
& -\frac{m V_{h d s} T_{c}}{T_{c} V_{h d s}+T_{h}\left(V_{c d s}+S_{P} x_{0}+S_{d} y_{0}\right)}
\end{aligned}
$$

The total heat received from the hot source, can be calculated as follows:

$$
\begin{aligned}
& Q_{h} \\
& =\frac{m r T_{c}}{T_{c}-T_{h}}\left(\ln \left(\frac{T_{c}\left(V_{h d s}+S_{d} y_{0}\right)+T_{h} V_{c d s}}{T_{c} V_{h d s}+T_{h}\left(V_{c d s}+S_{d} y_{0}\right)}\right)\right. \\
& \left.+\ln \left(\frac{T_{c} V_{h d s}+T_{h}\left(V_{c d s}+S_{P} x_{0}+S_{d} y_{0}\right)}{T_{c}\left(V_{h d s}+S_{d} y_{0}\right)+T_{h}\left(V_{c d s}+S_{P} x_{0}\right)}\right)\right) \\
& +\Delta m \frac{r\left(1-\eta_{r e g}\right)}{\gamma-1}\left(T_{h}-T_{c}\right)
\end{aligned}
$$

The total heat released to the cold source is determined as follows: 


$$
\begin{aligned}
& Q_{c} \\
& =-\frac{m r T_{c}^{2}}{T_{c}-T_{h}}\left(\ln \left(\frac{T_{c}\left(V_{h d s}+S_{d} y_{0}\right)+T_{h} V_{c d s}}{T_{c} V_{h d s}+T_{h}\left(V_{c d s}+S_{d} y_{0}\right)}\right)\right. \\
& \left.+\ln \left(\frac{T_{c} V_{h d s}+T_{h}\left(V_{c d s}+S_{P} x_{0}+S_{d} y_{0}\right)}{T_{c}\left(V_{h d s}+S_{d} y_{0}\right)+T_{h}\left(V_{c d s}+S_{P} x_{0}\right)}\right)\right) \\
& -\Delta m \frac{r\left(1-\eta_{r e g}\right)}{\gamma-1}\left(T_{h}-T_{c}\right)
\end{aligned}
$$

The total efficiency of the engine is as follows:

$$
\eta_{t}=1-\frac{\frac{h}{v} S_{d}\left(T_{c}-T_{C}\right)}{\frac{h}{v} S_{d}\left(T_{H}-T_{h}\right)}
$$

The total power of the engine based on Stirling ideal cycle, is as follows:

$$
\text { Power }=h S_{d}\left(T_{H}-T_{h}\right)-h S_{d}\left(T_{c}-T_{C}\right)
$$

And finally, the flywheel rotation speed will be as follows:

$$
\omega=2 \pi v
$$

The purpose of this article is to control the Stirling engine flywheel rotation speed. Therefore, displacer and power pistons' movement and their speed should be adjusted in such a way so that the desired angular velocity is achieved. For this purpose, hot sink temperature must be controlled. For controlling the hot sink temperature, a testbed must be set up to evaluate the engine performance, and based on the obtained information from this testbed, the engine control program can be established.

\section{Stirling engine testbed}

The testbed is considered for this study includes an LTD Stirling engine, a temperature controller, a data logger, and a computer. Figure 3 shows the fabricated LTD Stirling engine. This engine consists of hot and cold sinks, a crankshaft and a flywheel, power cylinder and piston, and displacer cylinder and piston. In this engine, a rubber diaphragm is used as the power piston and the displacer piston is made of a lightweight material to be able to move easily due to the type of the engine. Since this engine is a kind of low temperature, by any conventional heat source, it can be started up. In this experiment, two electric heaters are used as the heat source. The working fluid used for this engine is air and its pressure is the pressure of the air at that location.

The engine working steps are as follows: first of all, the hot sink which is located at the bottom of the engine receives heat from the heaters and releases this energy to the working fluid (air) in the displacer cylinder. After that, hot and expanded air moves to the power cylinder, causes the power piston (diaphragm) to move. By the diaphragm displacement, the crankshaft that is connected to it through a connecting rod starts to rotate. By rotation of the crankshaft, the displacer starts to come back to its first place, causing working fluid to receive heat from the hot sink, again. This process continues repeatedly until the hot source stops exchanging heat to the hot sink.

In this engine, there is a hole for passing of the displacer piston rod, but its diameter is a little bigger than the rod. The reason for this extra diameter is to let hot air pass through this hole and fresh air comes back to the displacer cylinder.

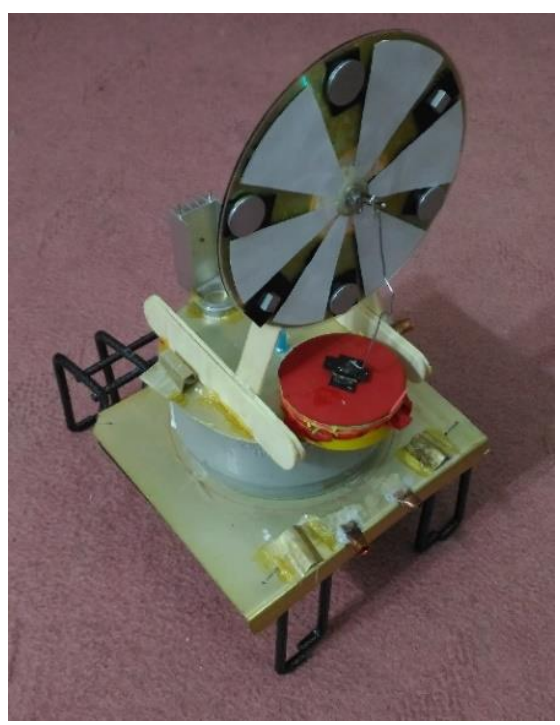

Figure 3 An LTD Stirling engine

The temperature control system as shown in Figure 4, has a temperature sensor that is installed on the hot sink and based on the read temperature, it turns on and off its heaters so that hot sink temperature reaches the desired range. This controller has two output channels for powering two heaters with different power ranges, which are used for better controlling the hot sink temperature.

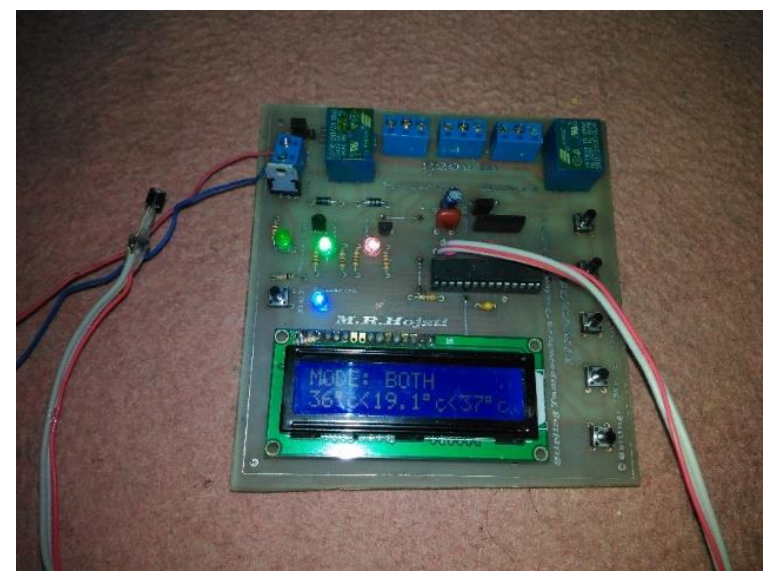

Figure 4 Temperature controller

For measuring engine working data and its performance, a data logger as shown in Figure 5, is used. This data logger records hot sink and cold sink temperatures, ambient temperature, and flywheel rotation speed with its temperature and the Hall Effect sensors and then sends them to the computer. It should be noted that on the surface 
of the flywheel, 6 magnet pieces are installed to let the Hall Effect sensor record more accurate data.

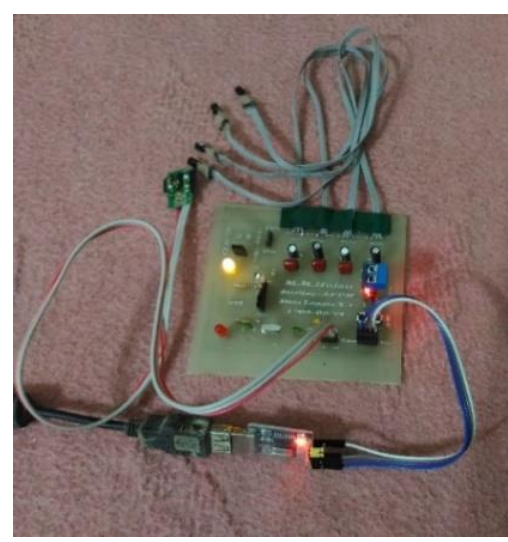

Figure 5 Data logger

The seats for the temperature controller and data logger temperature sensors on the engine sinks are shown in Figure 6. As it is clear in the picture, copper and aluminum cases are used for the sensors and this is because of their low thermal inertia that makes a faster time response for them.

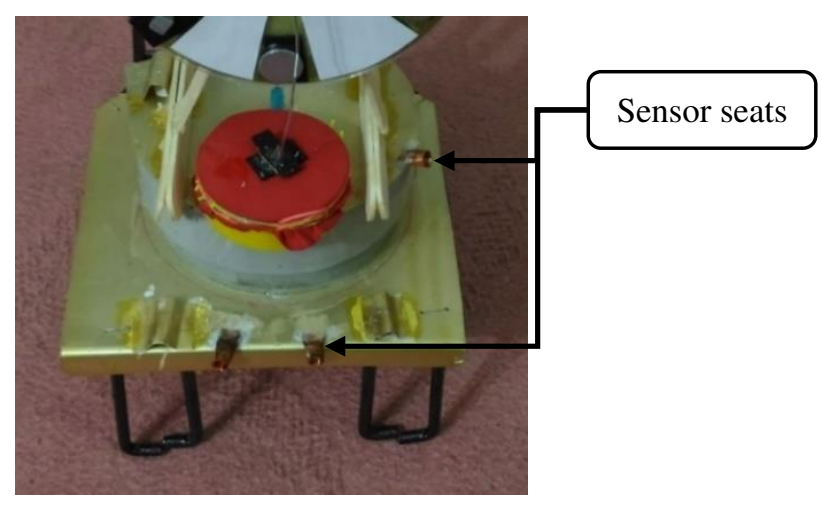

Figure 6 Sensor seats on the sinks

Now, it is time to design and train a neural network by using the obtained information so that in this way, the engine can be controlled.

\section{Results and Discussion}

As mentioned earlier, to control the Stirling engine a neural network is needed so that by using the data which is provided by this network, the engine hot sink temperature be under control, and thereby, the engine speed can be under control as well. To train the neural network, the training data is needed, therefore, it is required at first that in several different statuses, the engine operation is recorded and after that, the neural network is trained based on this data.

\subsection{Training data preparation}

As noted above, to create a neural network and train it, firstly it is necessary to provide the training data. The data has been obtained by the test bed shown in Figure 7 .

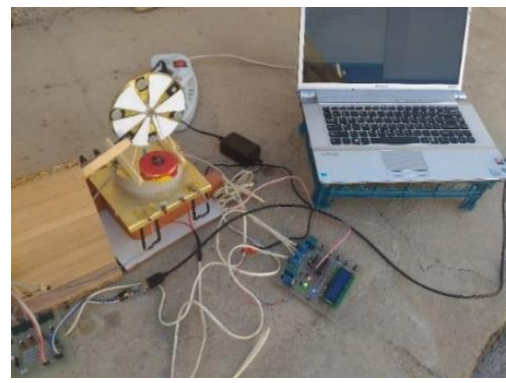

Figure 7 LTD Stirling engine testbed

Figure 8 shows an example of this engine operation in the testing environment temperature, recorded by the data logger.

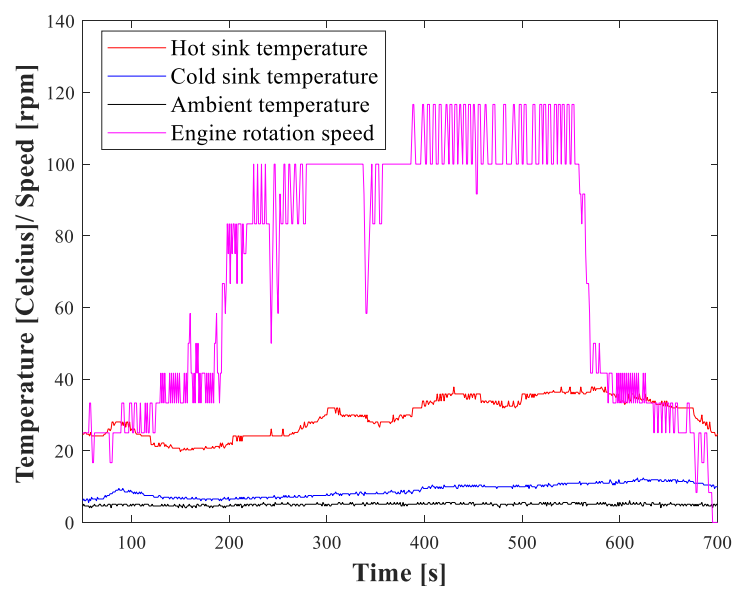

Figure 8 Stirling engine performance graph in an ambient temperature condition

To train the ANN, 650 samples taken from the diagram, is intended.

\subsection{Creating the neural network}

To prepare the neural network, MATLAB nntool toolbox is used. For this network, 50 neurons are considered for the hidden layer with the tangent sigmoid (TANSIG) transfer function and for the output layer, one neuron with PURELIN transfer function is chosen. Figure 9, shows the network schematic structure.

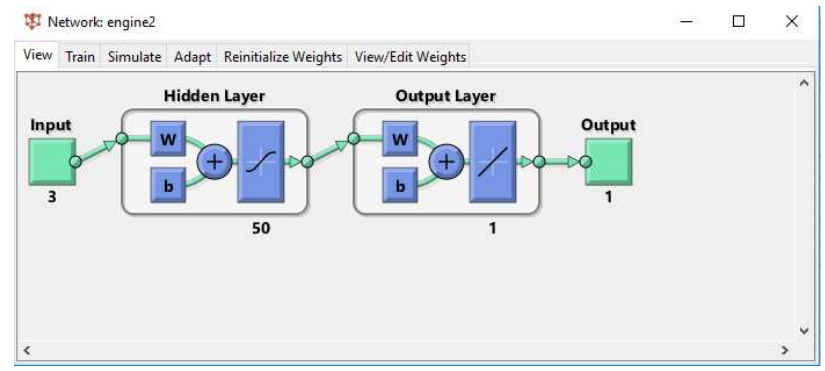

Figure 9 Neural network defined for the engine 
As is mentioned above, the training data includes 650 engine operating points. The input data includes cold sink and air (ambient) temperatures and the flywheel rotation speed. Hot sink temperature is the output data. As seen in Figure 8, since there are disturbing factors such as engine components friction, flywheel rotation speed has reduced for a few moments in different points. ANN performance and regression graphs are shown in Figure 10 and Figure 11.

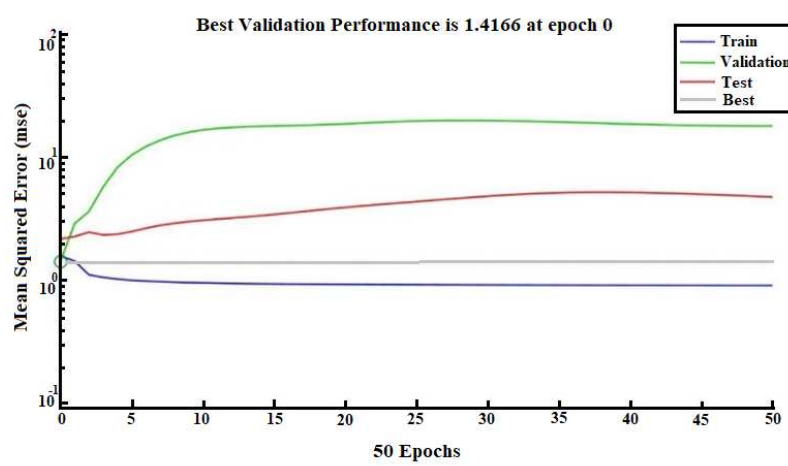

Figure 10 Neural network performance graph
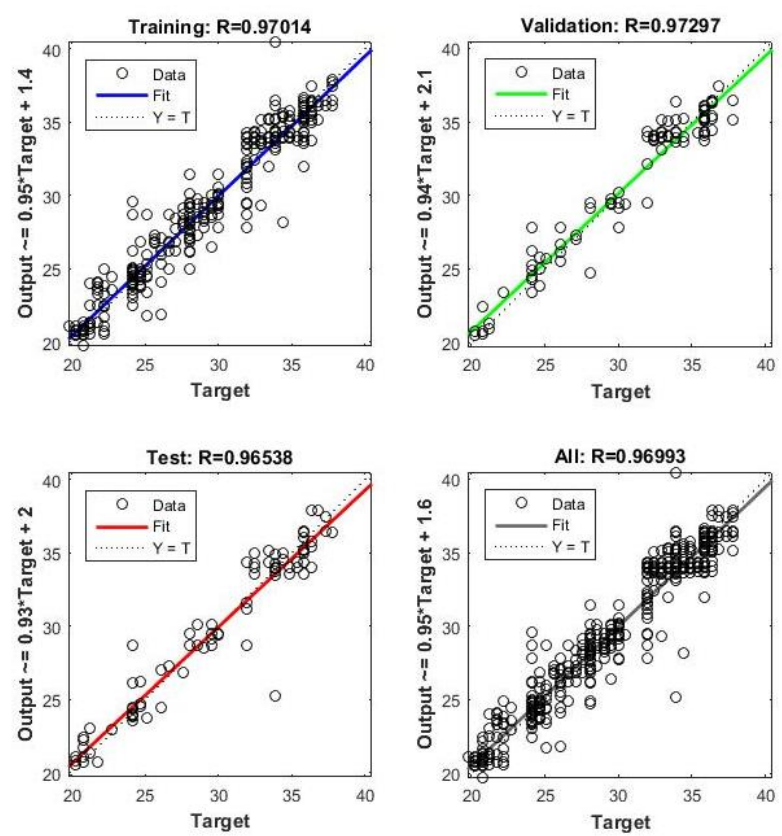

Figure 11 The neural network regression graph

\subsection{Neural network testing}

After training the network, it is necessary to check ANN performance to determine if it is accurate enough. Therefore, its output data should be compared with the engine hot sink temperature through specified points. To test the network, an input matrix was created with the data that was mentioned before. After that, the output data created by the network is compared with the real hot sink temperature. Figure 12, shows the results.

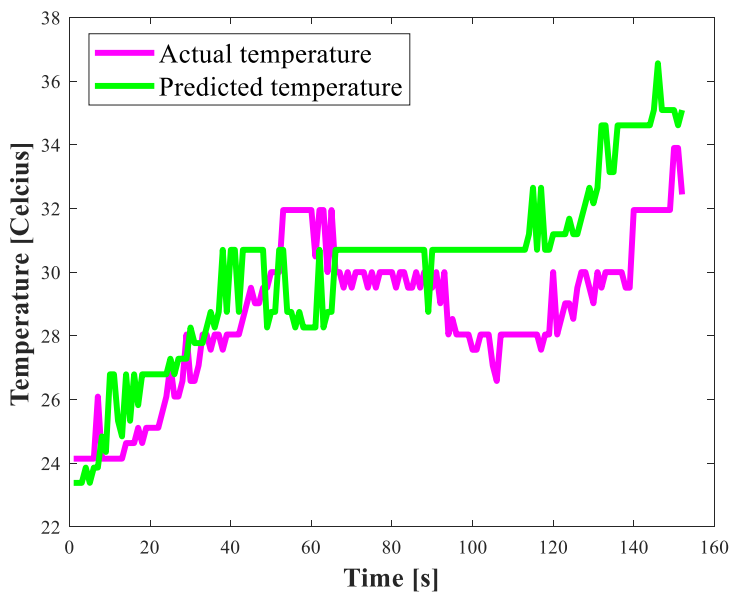

Figure 12 Comparison between ANN output and the real hot sink temperature

In the figure above, the real temperature and the predicted temperature are not exactly the same but since their difference are small, this issue can be overlooked.

\subsection{Practical testing of created neural network}

At this point, the network should be tested practically in real conditions to be determined if it is capable of calculating the hot sink temperature so that by applying it, flywheel velocity reaches the desired constant speed. In this test, the purpose is to stabilize speed around $100 \mathrm{rpm}$. Therefore, 100 was imported manually to the neural network as speed data and cold sink and air temperatures were imported from the sensors. The output data from the neural network which was hot sink temperature was applied to the heat controller, manually and it was bringing hot sink temperature to the specified level. Thus, the engine was working at the speed around the desired velocity. Figure 13 shows the engine performance in the new conditions.

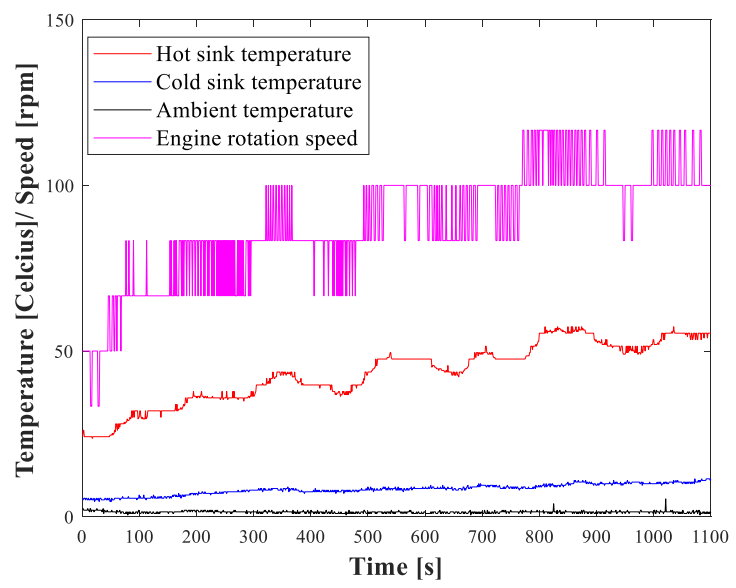

Figure 13 Engine performance using neural network determines

As in the graph is shown, there are some irregularities. These problems may have happened for the following reasons:

1. Setting the temperature of the controller manually and with some delays. 
2. Engine components friction.

3. The neural network errors, which show that the network is needed to learn more.

4. The time delays created during the process. load should be added to the network so that the intelligent system can determine more accurate outputs.

\section{Conclusion}

As seen in this article, intelligent controlling of a Stirling engine to maintain its flywheel rotation speed in the range of desired speed, was examined. Flywheel speed, hot, cold and ambient temperatures, are the parameters in this engine that are evaluated.

Since the discovery of the relationship between these parameters is out of human ability, utilizing artificial intelligence can solve this problem properly. However, other parameters such as friction between the components of the engine are influential to its performance, but because of their relatively uniform effects on different engine working points, they are ignored.

One of the most useful tools in dealing with control issues is the use of ANN. The network was proposed for this problem is the type Feed-forward backpropagation with 50 neurons in the hidden layer with TANSIG function and one neuron in the output layer with PURELIN function. This network was taught initially by using recorded data of engine works in a series of working points and after that, its performance was tested to be determined whether the network output values coordinate with the real values; and then, the results of this comparison were presented in a graph. Finally, the main aim of this project which was Stirling engine speed control using ANN was investigated and the results were presented.

The results showed that the network with an error of as much as $6.99 \mathrm{e}-05$ was effective in determining the temperature of the hot sink. Not using intelligent control, means complete loss of engine speed control; since without utilizing artificial intelligence, not only determining hot sink temperature is time-consuming, but also having an online and precise temperature determination is impossible. Therefore, the use of neural networks in regards to speed and accuracy it has can solve this problem effectively. Last but not least, suggestions for further researches can be presented as follows:

1. In this study, because the temperature set by the neural network controller was not applied online, some beats have appeared in the rotation speed. Therefore, in the case of optimizing the control system, it is expected to have smoother results.

2. Coupling the Stirling engine to a generator in which the engine is controlled by the intelligent system, would be very useful because the generator can be quickly set up by its nominal working speed in different environmental conditions. But it should be noted that to achieve this purpose, other parameters such as generator

\section{References}

[1] A. Tavakolpour-Saleh and H. Jokar, "Neural network-based control of an intelligent solar Stirling pump," Energy, vol. 94, pp. 508-523, 2016.

[2] M. H. Ahmadi, M. Mehrpooya, and N. Khalilpoor, "Artificial neural networks modelling of the performance parameters of the Stirling engine," International Journal of Ambient Energy, vol. 37, no. 4, pp. 341-347, 2016.

[3] M. H. Ahmadi, M. A. Ahmadi, S. A. Sadatsakkak, and M. Feidt, "Connectionist intelligent model estimates output power and torque of stirling engine," Renewable and Sustainable Energy Reviews, vol. 50, pp. 871-883, 2015.

[4] Y. Ö. Özgören, S. Çetinkaya, S. Sarıdemir, A. Çiçek, and F. Kara, "Predictive modeling of performance of a helium charged Stirling engine using an artificial neural network," Energy conversion and Management, vol. 67, pp. 357368, 2013.

[5] M. H. Ahmadi, S. S. G. Aghaj, and A. Nazeri, "Prediction of power in solar stirling heat engine by using neural network based on hybrid genetic algorithm and particle swarm optimization," Neural Computing and Applications, vol. 22, no. 6, pp. 1141-1150, 2013.

[6] R. M. Balabin, E. I. Lomakina, and R. Z. Safieva, "Neural network (ANN) approach to biodiesel analysis: analysis of biodiesel density, kinematic viscosity, methanol and water contents using near infrared (NIR) spectroscopy," Fuel, vol. 90, no. 5, pp. 2007-2015, 2011.

[7] A. Chouai, S. Laugier, and D. Richon, "Modeling of thermodynamic properties using neural networks: Application to refrigerants," Fluid Phase Equilibria, vol. 199, no. 1, pp. 53-62, 2002.

[8] H. Jokar and A. Tavakolpour-Saleh, "A novel solar-powered active low temperature differential Stirling pump," Renewable Energy, vol. 81, pp. 319-337, 2015.

[9] M. H. Ahmadi, M. A. Ahmadi, R. Bayat, M. Ashouri, and M. Feidt, "Thermo-economic optimization of Stirling heat pump by using nondominated sorting genetic algorithm," Energy Conversion and Management, vol. 91, pp. 315322, 2015.

[10] S. Toghyani, A. Kasaeian, and M. H. Ahmadi, "Multi-objective optimization of Stirling engine using non-ideal adiabatic method," Energy Conversion and Management, vol. 80, pp. 54-62, 2014. 
[11] M. H. Ahmadi, H. Hosseinzade, H. Sayyaadi, A. H. Mohammadi, and F. Kimiaghalam, "Application of the multi-objective optimization method for designing a powered Stirling heat engine: design with maximized power, thermal efficiency and minimized pressure loss," Renewable Energy, vol. 60, pp. 313-322, 2013.

[12] M. H. Ahmadi, A. H. Mohammadi, S. Dehghani, and M. A. Barranco-Jimenez, "Multi-objective thermodynamic-based optimization of output power of Solar Dish-Stirling engine by implementing an evolutionary algorithm," Energy conversion and Management, vol. 75, pp. 438445, 2013.

[13] R. Li, L. Grosu, and D. Queiros-Conde, "Multiobjective optimization of Stirling engine using Finite Physical Dimensions Thermodynamics (FPDT) method," Energy Conversion and Management, vol. 124, pp. 517-527, 2016.

[14] M. H. Ahmadi, M. A. Ahmadi, F. Pourfayaz, M. Bidi, H. Hosseinzade, and M. Feidt, "Optimization of powered Stirling heat engine with finite speed thermodynamics," Energy Conversion and Management, vol. 108, pp. 96105, 2016.

[15] V. Patel and V. Savsani, "Multi-objective optimization of a Stirling heat engine using TSTLBO (tutorial training and self learning inspired teaching-learning based optimization) algorithm," Energy, vol. 95, pp. 528-541, 2016.

[16] R. Arora, S. Kaushik, R. Kumar, and R. Arora, "Multi-objective thermo-economic optimization of solar parabolic dish Stirling heat engine with regenerative losses using NSGA-II and decision making," International Journal of Electrical Power \& Energy Systems, vol. 74, pp. 25-35, 2016.

[17] M. H. Ahmadi, M. A. Ahmadi, A. Mellit, F. Pourfayaz, and M. Feidt, "Thermodynamic analysis and multi objective optimization of performance of solar dish Stirling engine by the centrality of entransy and entropy generation," International Journal of Electrical Power \& Energy Systems, vol. 78, pp. 88-95, 2016.

[18] Z. Luo, U. Sultan, M. Ni, H. Peng, B. Shi, and G. Xiao, "Multi-objective optimization for GPU3 Stirling engine by combining multi-objective algorithms," Renewable Energy, vol. 94, pp. 114$125,2016$. 